\title{
ÁREAS VERDES URBANAS E PERIURBANAS DO MUNICÍPIO DE MIMOSO DO SUL-ES, BRASIL
}

Caio Henrique Ungarato Fiorese ${ }^{1}$, Laureanny Madeira ${ }^{1}$, Gilson Silva Filho ${ }^{1}$, Daniel Henrique Breda Binoti ${ }^{1,2}$, Lima Deleon Martins ${ }^{1,3}$.

${ }^{1}$ Centro Universitário São Camilo, Cachoeiro de Itapemirim, Espírito Santo, Brasil. (caiofiorese@hotmail.com).

${ }^{2}$ DAP Florestal, Diretor de Pesquisa e Desenvolvimento, Viçosa, Minas Gerais, Brasil.

${ }^{3}$ Geotechnology Applied to Global Environment - CNPq Advanced Research Group GAGEN, Alegre, Espírito Santo, Brazil.

Recebido em: 22/09/2018 - Aprovado em: 23/11/2018 - Publicado em: 03/12/2018 DOI: 10.18677/EnciBio 2018B9

As áreas verdes urbanas são de grande importância econômica, ambiental e paisagística em uma cidade, sendo que a ausência ou o manejo incorreto dessa vegetação pode acarretar problemas ambientais sérios. O objetivo deste estudo foi avaliar as áreas verdes urbanas e periurbanas do município de Mimoso do Sul/ES e propor medidas para diagnosticar possíveis problemas da arborização local. As áreas verdes foram manipuladas utilizando imagens em altíssima resolução de ortofotomosaico e o banco de dados de municípios, ambos disponibilizados pelo Geobases/ES. No programa ArcGIS, os procedimentos ocorreram por fotointerpretação: foi delimitada a zona urbana para que, posteriormente, delimitar as áreas de arborização e faixas de verde (gramíneas); e uso de solo na zona periurbana com um buffer de 400 metros. Foi estimado o Índice de Áreas Verdes (IAV) da referida cidade e foram estudadas as porcentagens de áreas verdes obtidas. Na faixa periurbana, as áreas arborizadas foram analisadas considerando uma expansão da zona urbana. As áreas verdes da cidade estão fragmentadas, e mais aglomeradas nas Áreas de Preservação Permanente. Obteve-se o IAV equivalente a 16,69 $\mathrm{m}^{2} / \mathrm{hab}$, estando acima do mínimo requerido pela OMS e SBAU. $\mathrm{Na}$ zona periurbana, predominam áreas de agropecuária, com $23,81 \%$ de florestas. A arborização das zonas urbana e periurbana requer preservação e conservação, devido ao IAV estimado, sendo importante a criação de parques urbanos, preservação da mata ciliar e atividades de educação ambiental.

PALAVRAS-CHAVE: Arborização Pública; Geotecnologias; Manejo e Uso de Solo.

\section{URBAN AND PERIPHERAL GREEN AREAS OF THE MUNICIPALITY OF MIMOSO DO SUL - ES, BRAZIL}

\footnotetext{
ABSTRACT

Urban green areas are of great economic, environmental and landscape importance in a city, and the absence or incorrect management of these vegetation can cause serious environmental problems. The objective of this study was to evaluate the urban and peripheral green areas of the municipality of Mimoso do Sul / ES and ENCICLOPÉDIA BIOSFERA, Centro Científico Conhecer - Goiânia, v.15 n.28; p. 97 2018
} 
propose measures to diagnose possible local afforestation problems. The green areas were manipulated using very high orthophotomousic images and the database of municipalities, both made available by Geobases / ES. In the ArcGIS program, the procedures were performed by photointerpretation: the urban zone was delimited so that, later, delimiting the areas of afforestation and bands of green (grasses); and use of soil in the peripheral zone with a buffer of 400 meters. The Green Areas Index (IAV) of this city was estimated and the percentages of green areas obtained were studied. In the peripheral area, the forested areas were analyzed considering an expansion of the urban area. The green areas of the city are fragmented, and more crowded in the Areas of Permanent Preservation. The IAV equivalent to $16.69 \mathrm{~m}^{2} /$ inhabitant was obtained, being above the minimum required by the WHO (World Health Organization) and SBAU (Brazilian Urban Afforestation Society). In the peripheral zone, areas of agriculture and livestock predominate, with $23.81 \%$ of forests. The afforestation of the urban and peripheral areas requires preservation and conservation, due to the estimated BTI, being important the creation of urban parks, preservation of the riparian forest and environmental education activities.

KEYWORDS: Public Afforestation; Geotechnology; Management and Use of Soil.

\section{INTRODUÇÃO}

A preocupação com os problemas que afetam o meio ambiente vem merecendo atenção a partir das três últimas décadas devido à degradação ambiental provocada pelo atual modelo de desenvolvimento urbano, que não conta com um planejamento ambiental adequado, enfatizando os casos das áreas verdes nas cidades (MUACUVEIA, 2017). Martines (2015) enfatiza o crescimento desordenado das cidades traz como uma das consequências a falta de áreas (locais de lazer, com arborização, entre outros) para atenuar os impactos do acelerado processo de urbanização.

O Código Florestal Brasileiro conceitua área verde urbana como sendo "espaços, públicos ou privados, com predomínio de vegetação, preferencialmente nativa, natural ou recuperada, previstos no Plano Diretor, nas Leis de Zoneamento Urbano e Uso do Solo do Município, indisponíveis para construção de moradias" (BRASIL, 2012). De acordo com Amato-Lourenço et al. (2016), a infraestrutura das áreas verdes nas cidades pode ser composta por parques, florestas, praças, hortas comunitárias, arborização urbana e tetos verdes.

A importância da cobertura vegetal, tanto em áreas urbanas como distante delas, está na manutenção e no equilíbrio do ambiente como, por exemplo, proteção contra assoreamento dos cursos hídricos, diminuição da erosão ao proteger os solos e regularização dos regimes hídricos (RUBIRA, 2016). Segundo Maciel e Barbosa (2015), para vários pesquisadores, a vegetação é considerada um relevante indicador de qualidade ambiental urbana. Panasolo et al. (2014) enfatizam o aumento da importância dada às áreas verdes urbanas no contexto de preservação ambiental e políticas públicas voltadas à qualidade de vida nos centros urbanos. No caso dos parques urbanos, Szeremeta e Zanin (2013) destacam que as condições ambientais adequadas dessas áreas, como a arborização, contribuem no bem-estar e na saúde da população de uma cidade.

A ausência dos espaços verdes nas cidades causa sérias consequências e prejuízos, tanto para população, quanto para o meio ambiente (BONFANTI et al., 2017), acarretando, por exemplo, desequilíbrios ambientais, diminuição da biodiversidade, alterações das condições climáticas, desconforto térmico, vários 
tipos de poluição, congestionamentos e risco de acidentes naturais ou humanos, em escalas que vão do local ao regional (SCHEUER; NEVES, 2016). Nos centros urbanos, o conjunto desses fatores tem provocado efeitos nocivos à saúde e ao bem-estar humano (PANASOLO et al., 2014).

De acordo com Pinheiro e Souza (2017), a construção e ampliação da zona urbana é resultado do desmatamento de áreas verdes, havendo um grande espaço ocupado por mancha urbana que traz consequências notórias para a região. Segundo os mesmos autores, a construção de vias e loteamentos nesses locais afeta drasticamente fauna e flora.

As sociedades atuais apresentam um panorama direcionado ao processo de urbanização. Contudo, apesar dos avanços tecnológicos e científicos, as cidades ainda enfrentam uma série de problemas, muitos deles relacionados ao ambiente local, que aumentam cada vez mais nos espaços urbanos (SILVA et al., 2014).

As informações quanto áreas verdes urbanas em várias cidades do estado do Espírito Santo ainda é escasso. Desta forma, um estudo das áreas verdes locais pode contribuir para a elaboração de políticas públicas, com intuito de minimizar alguns dos problemas ambientais existentes nas cidades capixabas (PIROVANI et al., 2012). O objetivo deste estudo foi avaliar as áreas verdes urbanas e periurbanas do município de Mimoso do Sul-ES considerando a urbanização e propor medidas para diagnosticar possíveis problemas advindos da arborização urbana no referido local.

\section{MATERIAL E MÉTODOS}

Foi considerado como local de estudo o município de Mimoso do Sul, que se localiza na região sul Caparaó do Estado do Espírito Santo, a uma latitude sul de $21^{\circ}$ 03'50,40" e a uma longitude, a oeste de Greenwich de 41'21'57,60". Possui solos com predominância latossolo vermelho amarelo distrófico, clima tropical quente, com maior ocorrência de chuvas entre os meses de outubro a março (INCAPER, 2010).

No mapeamento das áreas verdes urbanas, foram utilizados blocos de imagens de ortofotomosaico disponibilizado pelo Sistema Integrado de Bases Geoespaciais do Estado do Espírito Santo (GEOBASES) referente ao levantamento realizado nos anos de 2012 a 2015, com resolução espacial de $25 \mathrm{~cm}$ e tamanho de $10 \times 10 \mathrm{Km}$. Além dessa ferramenta, também foi adquirido junto ao Instituto Nacional Jones dos Santos Neves (IJSN) o banco de dados geográficos referente à delimitação dos municípios do Espírito Santo. Por meio da sobreposição dos arquivos, o município de Mimoso do Sul, bem como seu perímetro urbano, foi identificado.

Para manusear os dados geográficos, foi utilizado o programa ArcGis, na versão 10.2.2. A zona urbana da sede do município foi delimitada por fotointerpretação das feições na escala 1:1000. Em seguida, a partir do limite do perímetro urbano traçado, as áreas verdes da faixa urbana de Mimoso do Sul foram delimitadas também por fotointerpretação, na mesma escala utilizada anteriormente.

Com intuito de identificar a análise e a diferenciação das áreas verdes locais, as mesmas foram classificadas de acordo com a classificação feita por autores como Pirovani et al. (2012) e Santos e Magri (2018), conforme mostrado no Quadro 1, e adaptadas conforme a realidade da área urbana de Mimoso do Sul.

Em seguida, foram mapeadas as áreas periurbanas de Mimoso do Sul que, são áreas que se localizam além dos subúrbios de uma cidade onde as atividades rurais e urbanas se misturam, não sendo possível definir os limites físicos e sociais 
destes espaços (PENSAMENTO VERDE, 2014), portanto, as áreas periurbanas ficam localizadas no intermédio das zonas urbanas e rurais de um município. No mapeamento das áreas verdes na zona periurbana, a partir do perímetro urbano da sede do município, através da ferramenta Buffer localizada no ícone Geoprocessing no ArcGis, foi traçada a área periurbana com 400 metros de largura. Essa distância foi considerada devido à pequena extensão urbana e ao baixo número de habitantes residentes, conforme as informações do Instituto Brasileiro de Geografia e Estatística (IBGE, 2010).

QUADRO 1. Classificação e respectivas descrições para as áreas verdes urbanas. Fonte: Pirovani et al. (2012); Santos e Magri (2018). Adaptado pelos autores (2018).

\begin{tabular}{|c|c|}
\hline Classe & Descrição \\
\hline Área arborizada & $\begin{array}{c}\text { Áreas públicas e particulares que } \\
\text { apresentam vegetação arbórea nativa } \\
\text { ou exótica, em contabilizando também } \\
\text { a arborização de praças }\end{array}$ \\
\hline Faixas de verde & $\begin{array}{c}\text { Consideram-se os gramados e } \\
\text { forrações (campos de futebol e campos } \\
\text { de golfe, caso exista) }\end{array}$ \\
\hline
\end{tabular}

Após a delimitação, as áreas verdes, bem como o uso de solo nessa região, foram mapeadas também com o auxílio de fotointerpretação em escala 1:1000, e classificadas de acordo com as observações obtidas pelos autores e conforme Santos e Magri (2018), segundo o exposto no Quadro 2.

QUADRO 2. Classificação e respectivas descrições para as áreas verdes periurbanas. Fonte: Santos e Magri (2018). Adaptado pelos autores (2018).

\begin{tabular}{|c|c|}
\hline 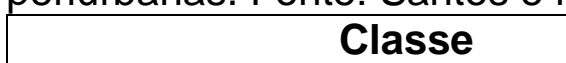 & Descrição \\
\hline Pasto Sujo & $\begin{array}{c}\text { Áreas onde foram desenvolvidas } \\
\text { atividades causando alteração da } \\
\text { vegetação natural. Após o abandono } \\
\text { destas, a vegetação natural começou a } \\
\text { se restabelecer, apresentando-se } \\
\text { atualmente em vários estágios } \\
\text { sucessionais }\end{array}$ \\
\hline Edificações & $\begin{array}{l}\text { Locais onde foi realizado algum tipo de } \\
\text { construção }\end{array}$ \\
\hline Pasto & $\begin{array}{l}\text { Área coberta por gramíneas, onde } \\
\text { árvores e arbustos são ausentes. }\end{array}$ \\
\hline Área arborizada & Área com vegetação arbórea. \\
\hline Agricultura & $\begin{array}{c}\text { Local com predomínio de café ou } \\
\text { outros cultivos agrícolas }\end{array}$ \\
\hline Solo exposto & $\begin{array}{c}\text { Área sem nenhum tipo de cobertura } \\
\text { vegetal e edificações }\end{array}$ \\
\hline Outros & $\begin{array}{c}\text { Áreas não identificadas ou com classes } \\
\text { diferentes (massa d'água e } \\
\text { pavimentação asfáltica, por exemplo) }\end{array}$ \\
\hline
\end{tabular}

A descrição de cada classe identificada no Quadro 2 foi de extrema 
importância, com intuito de tornar possível estabelecer um entendimento acerca da situação do uso de solo na zona periurbana. As classes edificações e solo exposto foram analisadas em conjunto com o término do mapeamento na zona periurbana, devido ao fato das duas classes terem a mesma resolução espectral. Essa etapa ocorreu com auxílio da ferramenta image classification, na barra de ferramentas do ArcGis, por meio da coleta de amostras de uso de solo. Foi considerado um número maior de amostras possível, para haver melhor precisão no mapeamento. As áreas de cada classe de uso de solo foram determinadas através da criação de um novo campo (denominado área) na tabela de atributos, considerando a área de cada pixel $\left(25 \times 25 \mathrm{~cm}^{2}\right)$ e o número de pixels. Após a classificação e quantificação das classes de áreas verdes urbanas e periurbanas, foi estimado Índice de Área Verde Total (IAVT). Para estimar o IAVT, foi considerada a metodologia empregada por autores como Duarte e Ziantonio Filho (2010), Harder et al. (2006), Pirovani et al. (2012). Esse cálculo ocorreu por meio do somatório das classes de áreas verdes do território urbano obtido durante o mapeamento dessas áreas, divido pelo número de habitantes do perímetro urbano, ou seja, (eq.1):

$$
\text { IAVT }=\frac{\sum \mathrm{AV}}{\mathrm{N}}
$$

Em que: $\mathrm{AV}=$ áreas verdes (em metros quadrados); $\mathrm{N}=$ número de habitantes da zona urbana. Duarte e Ziantonio Filho (2010) afirmam que esse índice é frequentemente utilizado para comparar as áreas verdes de diferentes cidades. $O$ número de habitantes foi consultado segundo estimativas realizadas pelo Instituto Brasileiro de Geografia e Estatística (IBGE, 2010) referente à área urbana da sede do município de Mimoso do Sul.

Após os cálculos do IAVT, o resultado obtido foi descrito com base na literatura considerada. As áreas verdes da zona periurbana foram analisadas levando em consideração o impacto de uma possível expansão da zona urbana do município estudado. $O$ valor obtido da área arborizada foi comparado em relação à área verde total e à área total da zona urbana. Os resultados foram avaliados com base nos valores mínimos de áreas verdes por habitante recomendados pela Organização Mundial da Saúde (OMS) e Sociedade Brasileira de Arborização Urbana (SBAU), em comparação com valores obtidos por outros pesquisadores em trabalhos similares a este.

No mapeamento das áreas verdes urbanas, foram analisadas a distribuição na cidade por meio da delimitação das Áreas de Preservação Permanente (APP), em comparação com as demais áreas verdes urbanas. Essa etapa foi de grande importância, pois de acordo com Chaves e Souza (2016), o levantamento da distribuição espacial das áreas verdes da malha urbana possibilitam tomadas de decisões no que diz respeito à gestão pública por ser possível saber quais locais precisam de maior atenção estruturação e introdução de áreas verdes. No ArcGis, foi delimitada uma largura de 30 metros para as APPs de todos os cursos hídricos que passam pela cidade, dada as características de largura dos cursos hídricos locais, determinadas pelas ferramentas de medição do programa, conforme aborda o Código Florestal Brasileiro (BRASIL, 2012). Foi estimado o valores totais de cobertura vegetal das APPs e do restante da área urbana arborizada. Em seguida, a distribuição das áreas verdes foi estudada com base na sua distribuição e nas características da cidade quanto a parques ecológicos e praças.

\section{RESULTADOS E DISCUSSÃO}


A Figura 1 e a Tabela 1 mostram, respectivamente, a distribuição das áreas verdes na zona urbana de Mimoso do Sul e os valores de cobertura vegetal contidas nas APPs e nos demais espaços urbanos. Silva et al. (2016), em estudos sobre as áreas verdes urbanas do município de Gurupi/TO, obtiveram para o valor do Índice de Área Verde Total equivalente a 1,46 $\mathrm{m}^{2} / \mathrm{hab}$. Segundo os mesmos autores, este valor está muito abaixo do mínimo recomendado, o que é um motivo de grande preocupação por se tratar de uma cidade com população residente na zona urbana inferior a 100.000 habitantes, assim como no município de Mimoso do Sul.

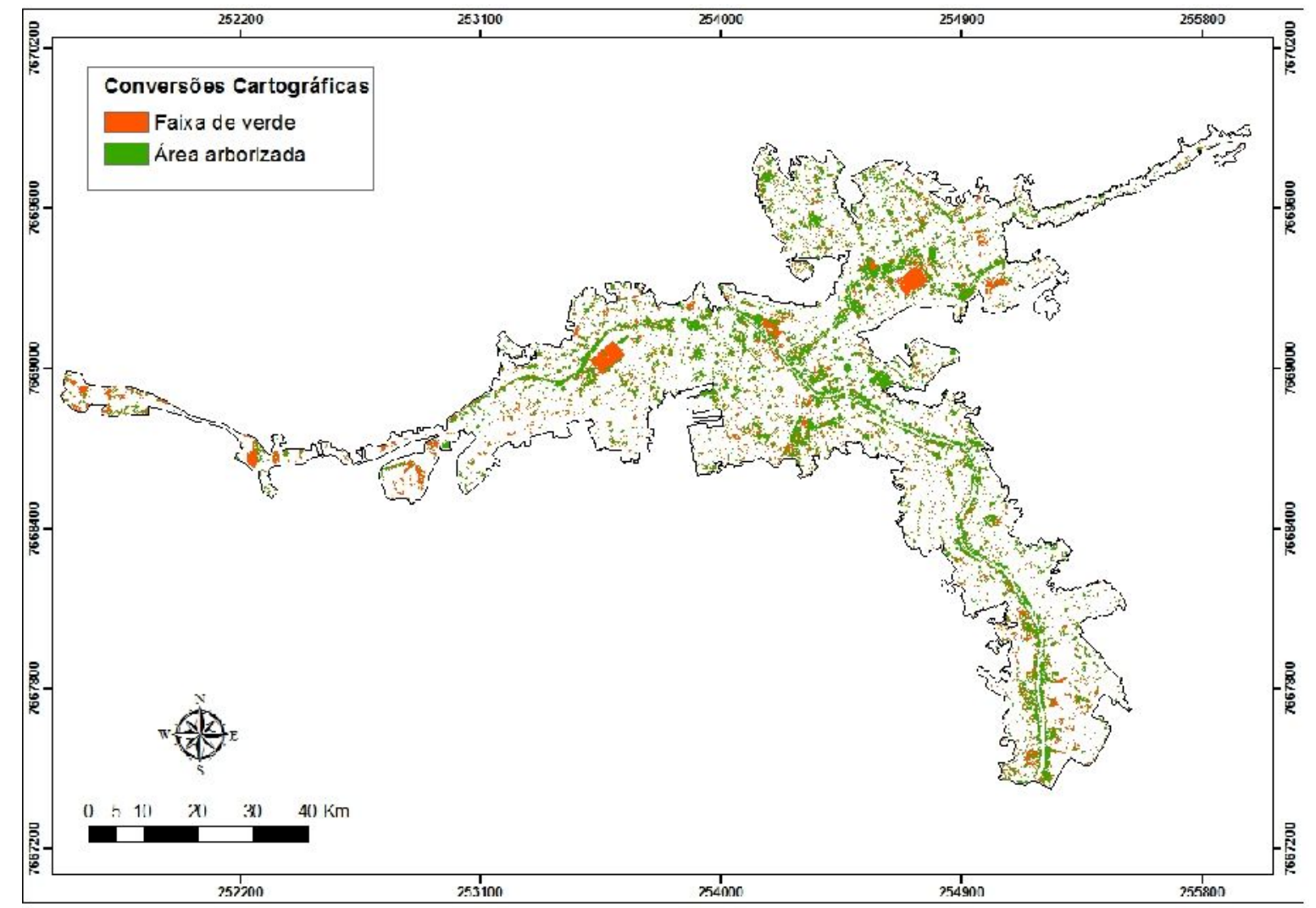

FIGURA 1. Distribuição das áreas verdes urbanas de Mimoso do Sul.

Fonte: Os Autores (2018).

TABELA 1. Área para cada classe de vegetação urbana nas APPs dos cursos hídricos da zona urbana de Mimoso do Sul.

\begin{tabular}{ccc}
\hline Classes & Área $\left(\mathbf{e m ~ m}^{2}\right)$ & Porcentagem (\%) \\
\hline Faixa verde & $28.095,75$ & 8,75 \\
\hline Arrea arborizada & $100.265,81$ & 31,23 \\
\hline Total & $128.361,56$ & 39,98 \\
\hline
\end{tabular}

A vegetação nas Áreas de Preservação Permanente em Mimoso do Sul corresponde a aproximadamente $40 \%$ da área total. Tsujii et al. (2014), analisando o uso e ocupação das áreas de preservação permanente para os municípios de Jataí e Rio Verde, detectaram, respectivamente, que apenas $20,13 \%$ e $16,34 \%$ se encontram preservadas. Portanto, Mimoso do Sul apresenta maiores áreas preservadas em comparação com outras cidades, porém, os valores obtidos indicam a necessidade de melhorias quanto ao aumento de áreas preservadas e a respectiva proteção das atividades antrópicas severas.

Em relação ao total de espaços verdes da zona urbana, as APPs abrigam 
cerca de $30 \%$ da vegetação da cidade. Silva (2012) afirma que a destinação das APPs para realização de atividades de recreação, lazer, educação, cultura e esporte, estando em harmonia e sustentabilidade com o meio biótico, podem transformá-las em um grande diferencial das cidades, proporcionando melhor qualidade de vida aos habitantes. Na cidade de Mimoso do Sul, a utilização sustentável dessas áreas é uma alternativa diante da falta de espaços verdes públicos.

$\mathrm{Na}$ Figura 1, nota-se que as áreas arborizadas estão mais aglomeradas, porém em menores quantidades (vide parágrafo anterior), próximas aos córregos e ao rio principal que corta a cidade. Nas demais áreas urbanas, a arborização se encontra bem fragmentada. Com relação às faixas de verde (campos e gramíneas), suas concentrações maiores estão presentes em campos de futebol e distribuídas em vários fragmentos em outras partes da cidade, sobretudo em quintais de residências e próximas a vias públicas.

Em um cenário ideal, a cobertura arbórea deve ser bem distribuída ao longo da zona urbana de um município. Dessa forma, é possível a conexão entre áreas verdes urbanas (parques e praças, por exemplo) com fragmentos florestais e áreas de proteção permanente, como margens de rios e córregos (MENDES et al., 2016). A área urbana de Mimoso do Sul não possui parques ecológicos, e apresenta pequenas praças. De maneira geral, a fragmentação dos locais arborizados indica que a arborização urbana do município poderia ser melhorada por meio da criação de parques ecológicos na zona urbana e outras áreas de lazer que contemplem vegetação arbórea, trazendo, assim, vários benefícios quanto à qualidade de vida e ambiental do referido município.

Considerando apenas as áreas verdes, conforme mostrado na Tabela 2, cerca de $63 \%$ é composto por arborização urbana, e 37\% corresponde a área verde de gramíneas e campos de futebol.

TABELA 2. Área para cada classe de vegetação urbana em Mimoso do Sul, considerando apenas as áreas verdes.

\begin{tabular}{ccc}
\hline Classes & Área $\left(\mathbf{e m ~} \mathbf{~ m}^{\mathbf{2}}\right)$ & Porcentagem (\%) \\
\hline Faixa verde & $157.626,31$ & 36,79 \\
\hline Área arborizada & $270.830,37$ & 63,21 \\
\hline Total & $428.456,69$ & 100 \\
\hline
\end{tabular}

Todavia, em relação à área total da zona urbana do município (conforme apresentado na Tabela 3), apenas $13,62 \%$ é composto por arborização, e 21,55\% representa faixas de verde.

TABELA 3. Porcentagem de cada classe de vegetação urbana da cidade de Mimoso do Sul, em relação à área total da zona urbana.

\begin{tabular}{cc}
\hline Classes & Porcentagem (\%) \\
\hline Faixa verde & 7,93 \\
\hline Área arborizada & 13,62 \\
\hline Total (em relação à área da zona urbana) & 21,55 \\
\hline
\end{tabular}

Melo et al. (2011) afirmam que as áreas de fragmentos florestais urbanos são alvos de manejo inadequado, que resultam da carência de profissionais habilitados para gerenciar de forma eficaz, contribuindo, assim, para a deterioração do ecossistema já modificado. Como a cidade de Mimoso do Sul na possui grandes fragmentos florestais, essa precaução deve ser considerada com maior ênfase nas 
Áreas de Preservação Permanente dos cursos hídricos que passam pela zona urbana, devido à maior concentração da arborização nesses locais.

Segundo as informações do Instituto Brasileiro de Geografia e Estatística (IBGE, 2010), a população residente na zona urbana de Mimoso do Sul referente ao censo de 2010 é de 16.226 habitantes. Considerando o valor de $270.830,37 \mathrm{~m}^{2}$, foi estimado o Índice de Área Verde e, com isso, foi obtido resultado igual a 16,69 $\mathrm{m}^{2} /$ habitante.

De acordo com Silva et al. (2016), os valores mínimos de referência recomendados do pela Organização Mundial da Saúde e pela Sociedade Brasileira de Arborização Urbana (SBAU) são, respectivamente, $12 \mathrm{~m}^{2} / \mathrm{hab}$ e $15 \mathrm{~m}^{2} / \mathrm{hab}$. Portanto, o município de Mimoso do Sul atende aos valores mínimos de áreas verdes por habitante. Entretanto, é importante ressaltar que um eventual crescimento populacional, de forma mais rápida, pode fazer com que haja queda nos índices de área verde, necessitando, assim, de algumas providências quanto à manutenção e aumento do IAVT.

Pirovani et al. (2012), em estudos sobre a arborização urbana da cidade de Cachoeiro de Itapemirim, obtiveram como resultado do IAVT igual a $35,04 \mathrm{~m}^{2} / \mathrm{hab}$. De acordo com os autores, o município possui $31,04 \%$ da vegetação urbana ocupada por arborização. Apesar de haver um número de habitantes da zona urbana bem maior em comparação com Mimoso do Sul, o valor obtido pelo índice foi mais elevado. No caso de Mimoso do Sul, sua zona urbana possui pequena extensão e a distribuição das áreas verdes ocorre em maior densidade somente em margens dos cursos hídricos da cidade, ao passo que Cachoeiro de Itapemirim possui fragmentos florestais em faixas maiores. Entretanto, Pirovani et al. (2012) enfatizam que o levantamento da cobertura vegetal pode variar muito conforme o método aplicado e, também, a delimitação da área urbana, sendo que o valor do IAV pode ser atribuído como um importante indicador de qualidade ecológica e ambiental do meio.

A presença/ausência de áreas verdes, por constituírem espaços livres cujo elemento fundamental de composição é a vegetação, pode contribuir na indicação de locais com melhor ou pior qualidade de vida (COSTA; FERREIRA, 2010). Isso pode ser observado, tomando como base os resultados de Pirovani et al. (2012), quando se compara o Índice de Desenvolvimento Humano (considerando a avaliação do ano de 2010) dos municípios de Cachoeiro de Itapemirim e Mimoso do Sul que são, respectivamente, 0,746 e 0,670, segundo o Atlas de Desenvolvimento Humano no Brasil (BRASIL). Portanto, uma possível melhoria na arborização urbana em Mimoso do Sul pode ser crucial para melhorar, mesmo que não em grande escala, a qualidade de vida nessa cidade. A Tabela 4 mostra as porcentagens de classes de uso de solo na zona periurbana de Mimoso do Sul.

TABELA 4. Porcentagem de uso de solo na área periurbana de Mimoso do Sul.

\begin{tabular}{cc}
\hline Classes & Porcentagem (\%) \\
\hline Pasto & 21,25 \\
\hline Solo exposto + área edificada & 2,34 \\
\hline Vegetação arbórea & 23,81 \\
\hline Pasto sujo & 19,68 \\
\hline Agricultura & 30,69 \\
\hline Outros & 2,23 \\
\hline As áreas totais de pastagem (pasto + pasto seco) correspondem a
\end{tabular}


aproximadamente $41 \%$, apresentando a maior predominância. A agricultura (principalmente o cultivo de café, que é de grande importância econômica para o município) possui também forte predomínio, ao passo que as áreas de arborização possuem maior porcentagem na zona periurbana.

A agricultura periurbana é capaz de contribuir para o desenvolvimento de um município na medida em que afeta e proporcione melhorias ambientais, sociais, econômicas e alimentares (SANTANA et al., 2017). Portanto, as atividades rurais realizadas nessas áreas precisam considerar, entre outros fatores, a preservação dos fragmentos florestais existentes e estar em consonância com a expansão urbana do município.

Um dos aspectos recorrentes e marcantes quando se pesquisa a respeito dos espaços periurbanos é em relação à sua posição intermediária, pois nessa localização, na maioria das vezes, são instaladas famílias urbanas em busca de amenidades rurais, no entanto, sem abrir mão dos serviços urbanos e do mercado de trabalho (PEREIRA, 2013). No município de Mimoso do Sul, devido ao número relativamente baixo de habitantes, a maior parte da população periurbana não é composta por indivíduos de classes mais elevadas. Contudo, caso essa situação seja alterada, o setor público municipal deverá adotar ações que visam o planejamento correto da infraestrutura ambiental e logística na área urbana e periurbana. A Figura 2 apresenta a distribuição das classes de uso de solo para a zona periurbana do município.

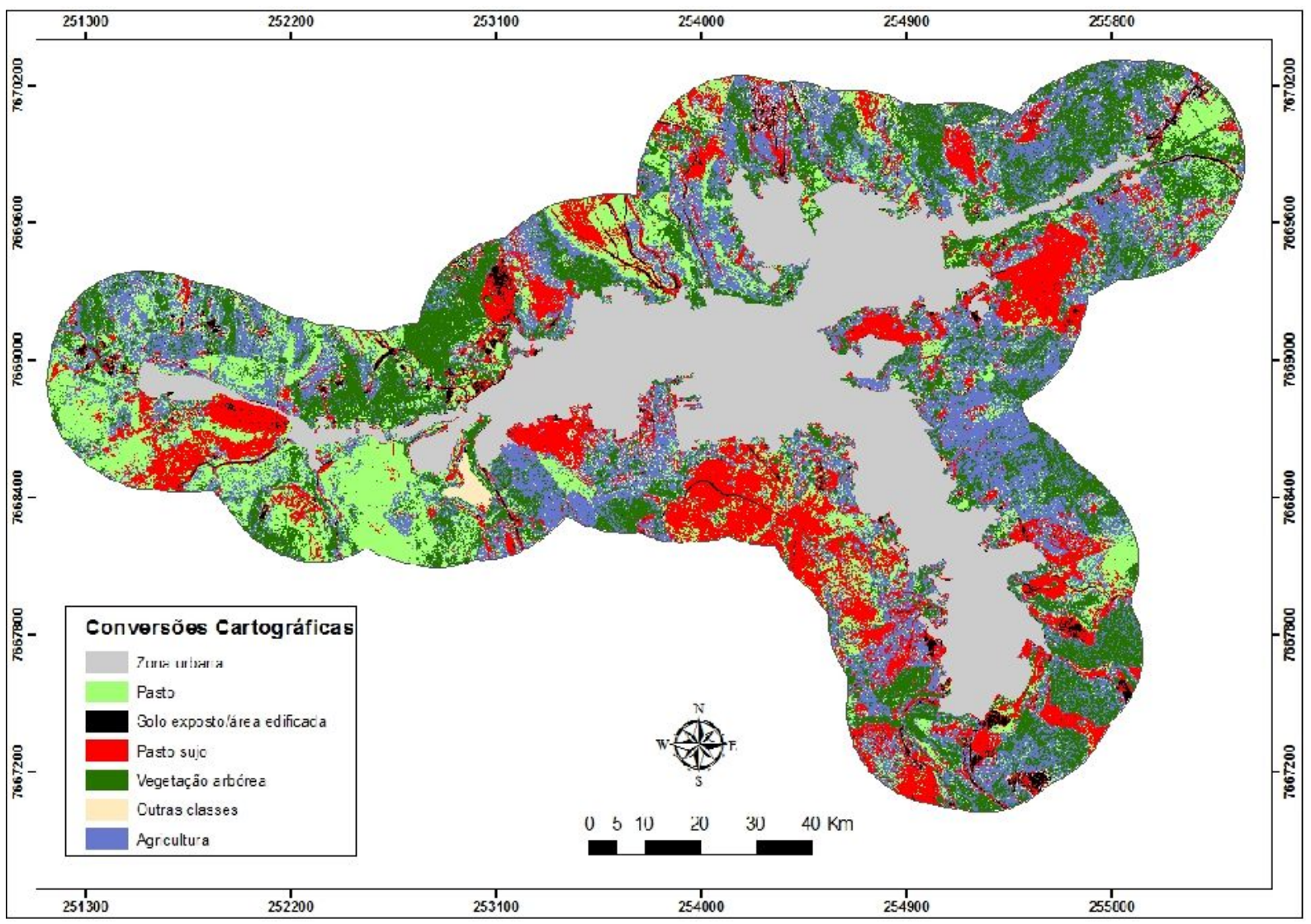

FIGURA 2. Uso de solo na zona periurbana de Mimoso do Sul. Fonte: Os Autores (2018).

De acordo com as análises de distribuição das classes de uso de solo, na 
zona periurbana, o município apresenta potenciais para uma eventual expansão urbana nas direções oeste e sudoeste, onde possuem a maior parte composta por pastagem e menores fragmentos de área arborizada. Com isso, a devastação da floresta periurbana e impermeabilização do solo trariam menores danos ambientais, considerando a expansão urbana nessas direções e a distribuição do uso de solo nos locais outrora degradados.

A retirada progressiva da paisagem natural em detrimento do crescimento das cidades provoca alterações no ambiente natural e/ou construído através de mudanças nos microclimas, topoclimas e mesoclimas em um município (COSTA; FERREIRA, 2010). Por isso, considerar o uso de solo em uma eventual expansão da zona urbana de Mimoso do Sul é de grande importância, sendo indispensável a adoção de medidas quanto a um manejo correto da vegetação e ótimo planejamento na infraestrutura por parte dos órgãos públicos do referido município.

As informações geradas e dispostas em mapas temáticos podem fornecer subsídios técnicos para diversas tomadas de decisões, objetivando ações de recuperação e fiscalização ambiental (SANTOS, 2018). Nas áreas periurbanas de Mimoso do Sul, a maior preocupação está na preservação de APPs próximas aos cursos hídricos e em topos de morro, pois a destruição dessas vegetações contribui na erosão do solo, sendo que os impactos podem ser percebidos na própria zona urbana em períodos de precipitação mais intensa ou escassez hídrica.

Melo Filho (2018) destaca que somente a gestão não garante ou contempla a dinâmica do espaço urbano, sendo necessário traçar um planejamento abordando metas a serem atingidas para obter sucesso nos resultados.

\section{CONCLUSÃO}

O Índice de Áreas Verdes estimado para a cidade de Mimoso do Sul está acima do mínimo recomendado pela Organização Mundial da Saúde (OMS) e Sociedade Brasileira de Arborização Urbana (SBAU), porém, inferior quando comparado a outras cidades brasileiras. Todavia, a distribuição das áreas verdes urbanas é irregular devido ao fato do município não ter reservas e parques ecológicos na parte urbana. A zona periurbana apresenta áreas de fragmentos florestais, no entanto, a mesma requer preservação e conservação desses espaços. Dessa forma, é de suma importância o setor público de Mimoso do Sul considerar essa informação no planejamento do município, além de propostas como, por exemplo, criação de parques urbanos, preservação da mata ciliar urbana e atividades de educação ambiental com a população, voltadas à importância das áreas verdes para o município. Considerando e pondo em prática esses fatores, a cidade de Mimoso do Sul dará um grande passo para alavancar o Índice de Área Verde e a qualidade de vida e ambiental na zona urbana.

\section{REFERÊNCIAS}

AMATO-LOURENÇO, L. F.; MOREIRA, T. C. L.; ARANTES, B. L. de.; SILVA FILHO, D. F. da.; MAUAD, T. Metrópoles, cobertura vegetal, áreas verdes e saúde. Estudos Avançados, v. 30, n. 86, p. 113-130, 2016. Disponível em: <http://www.scielo.br/sci elo.php?script=sci_arttext\&pid=S0103-40142016000100113>.

BONFANTI, C. G.; VALE, G. M. do.; RIBEIRO, J. G. Verificação espacial e determinação do índice de áreas verdes da cidade de Sinop-MT. Nativa, v. 6, n. 1, 2017. Disponível em: <http://revistanativa.com/index.php/revistanativa/article/view/3 
25/html>.

BRASIL. Lei $\mathbf{n}^{\circ}$ 12.651, de 25 de maio de 2012. Dispõe sobre a proteção da vegetação nativa e dá outras providências. Brasília, DF, 25 mai. 2012.

BRASIL. Atlas do desenvolvimento humano no Brasil. Disponível em: <http://ww w.atlasbrasil.org.br/2013/>. Acesso em: 10 jul. 2018.

CHAVES, A. M. S.; SOUZA, R. M. e. Indicadores de qualidade ambiental das áreas verdes públicas da cidade de Garanhuns-PE. Revista Equador (UFPI), v. 5, n. 5, p. 130-151, 2016. Disponível em: < http://www.ojs.ufpi.br/index.php/equador>.

COSTA, R. G. S.; FERREIRA, C. de C. M. Áreas verdes e qualidade de vida: aplicação do IAV na cidade de Juiz de Fora - MG. Disponível em: <http://www.geom orfologia.ufv.br/simposio/simposio/trabalhos/comunicacao_coordenada/010.pdf>.

Acesso em: 11 jul. 2018.

DUARTE, D. A. B. G.; ZIANTONIO FILHO, V. L. Índice de área verde por habitante para o município de Tumburi-SP. In: Encontro Nacional dos Geógrafos, 16, 2010, Porto Alegre. Anais do XVI Encontro Nacional dos Geógrafos. Porto Alegre: Associação Brasileira dos Geógrafos, 2010. Disponível em: < http://docplayer.com.br /17424649-Indice-de-area-verde-por-habitante-para-o-municipio-de-timburi-sp.html>.

GEOBASES - Sistema Integrado de Bases Geoespaciais do Estado do Espírito Santo. Imagens do mapeamento ES 2012-2015 disponíveis para download. Disponível em: <https://geobases.es.gov.br/novas-imagens-map-es-2012-2015-semecw>. Acesso em: 23 jun. 2018.

HARDER, I. C. F.; RIBEIRO, R. de C. S.; TAVARES, A. R. Índices de área verde e cobertura vegetal para as praças do município de Vinhedo, SP. Revista Árvore, Viçosa, v. 30, n. 2, p. 277-282, 2006. Disponível em: <http://www.scielo.br/scielo.php ?pid=S010067622006000200015\&script=sci_abstract\&tIng=pt>. doi: 10.1590/S0100 67622006000200015.

IBGE - Instituto Brasileiro de Geografia e Estatística, 2010. Sinopse do censo demográfico 2010 - Espírito Santo. Disponível em: <https://censo2010.ibge.gov.br /sinopse/index.php?dados=29\&uf=32>. Acesso em: 6 jul. 2018

INCAPER - Instituto Capixaba de Pesquisa, Assistência Técnica e Extensão Rural, 2010. Programa de assistência técnica e extensão rural PROATER 2011 - 2013. Disponível em: <https://incaper.es.gov.br/media/incaper/proater/municipios/Caparao/ Mimoso.pdf>. Acesso em: 20 jun. 2018.

MACIEL, T. T.; BARBOSA, B. C. Áreas verdes urbanas: história, conceitos e importância ecológica. CES Revista, v. 29, n. 1, p. 30-42, 2015. Disponível em: $<$ https://seer.cesjf.br/index.php/cesRevista/article/view/87/pdf_44>.

MARTINES, I. M. Remanescentes de áreas verdes e sua importância para a qualidade ambiental urbana: inserção de parâmetros analíticos, incluindo o 
geoprocessamento, aplicados ao estudo do Parque Estadual Chácara da Baronesa, Santo André/SP. Cidades Verdes, v. 3, n. 8, p. 78-104, 2015. Disponível em: $<$ https://www.amigosdanatureza.org.br/publicacoes/index.php/cidades_verdes/article /viewFile/986/1009>.

MElO, A. G. C. de.; CARVAlHO, D. A. de.; CASTRO, G. C. de.; MACHADO, E. L. M. Fragmentos florestais urbanos. Revista Científica Eletrônica de Engenharia Florestal, v. 17, n. 1, p. 58-79, 2011. Disponível em: < http://faef.revista.inf.br/image ns_arquivos/arquivos_destaque/Ozb1mN5pINQ3cZw_2013-4-29-11-34-29.pdf>.

MELO FILHO, J. M. M. Expansão urbana e impactos ambientais: uma análise dos projetos de intervenção urbana para a cidade de Teresina, Piauí. Geosaberes, v. 9, n. 19, p. 1-11, 2018. Disponível em: <http://www.geosaberes.ufc.br/geosaberes/articl e/view/664>. doi: https://doi.org/10.26895/geosaberes.v9i19.664.

MENDES, F. H.; PETEAN, F. C. S.; POLIZEL, J. L.; SILVA FILHO, D. F. Avaliação da fragmentação da cobertura arbórea de Maringá/PR urilizando geotecnologias. Scientia Plena, v. 12, n. 9, p. 1-9, 2016. Disponível em: <https://www.scientiaplena. org.br/sp/article/view/2984/1555>. doi: 10.14808/sci.plena.2016.090201.

MUACUVEIA, R. R. M. A inclusão do tema "áreas verdes urbanas" no programa de ensino de geografia da $12^{\mathrm{a}}$ classe em Moçambique. Revista Brasileira de Educação em Geografia, v. 7, n. 14, p. 161-184, 2017. Disponível em: <http://www. revistaedugeo.com.br/ojs/index.php/revistaedugeo/article/view/433/266>.

PANASOLO, A.; SILVA, J. C. G. L.; PETERS, E. L.; SANTOS, A. J. dos. Áreas verdes urbanas privadas de Curitiba: uma proposta de valorização para conservação (estudo de caso). Enciclopédia Biosfera, v. 10, n. 9, p. 2731-2744, 2014. Disponível em: <http://www.conhecer.org.br/enciclop/2014b/MULTIDISCIPLINAR/ar eas\%20verdes\%20urbanas.pdf>.

PENSAMENTO VERDE, 2014. "Você sabe o que é agricultura urbana ou periurbana?". Disponível em: <https://www.pensamentoverde.com.br/meio-ambient e/voce-sabe-o-que-e-agricultura-urbana-ou-periurbana/>.

PEREIRA, A. dos S. Análise das tendências de aplicação do conceito de periurbano. TerraPlural, v. 7, n. 2, p. 287-304, 2013. Disponível em: < http://www.revistas2.uepg. br/index.php/tp/article/view/4345>. doi: 10.5212/TerraPlural.v7i2.0007.

PINHEIRO, C. R.; SOUZA, D. D. de. A importância da arborização nas cidades e sua influência no microclima. Gestão e Sustentabilidade Ambiental, v. 6, n. 1, p. 67-82, 2017. Disponível em: < http://www.portaldeperiodicos.unisul.br/index.php/gestao_am biental/article/view/4179/3066>.

PIROVANI, D. B.; SILVA, A. G. da.; OLIVEIRA, O. M. de.; CALIMAN, J. P. Áreas verdes urbanas de Cachoeiro de Itapemirim, ES. Enciclopédia Biosfera, v. 8, n. 15, p. 171-179, 2012. Disponível em: < http://www.conhecer.org.br/enciclop/2012b/cienci as\%20agrarias/areas.pdf >. 
RUBIRA, F. G. Definição e diferenciação dos conceitos de áreas verdes/espaços livres e degradação ambiental/impacto ambiental. Caderno de Geografia, v. 26, n. 45, p. 134-150, 2016. Disponível em: < http://periodicos.pucminas.br/index.php/geogr afia/article/view/P.2318-2962.2016v26n45p134>. doi: 10.5752/p.2318-2962.

SANTANA, A. C. de.; SEQUEIRA, G. R.; OLIVEIRA, C. M. de.; GOMES, S. C. Mercado institucional e agricultura urbana e perirubana em Curuçambá, Ananindeua, Pará: oportunidades e desafios. Revista Brasileira de Gestão e Desenvolvimento Regional, v. 13, n. 1, p. 316-338, 2017. Disponível em: < http://www.rbgdr.net/revista /index.php/rbgdr/article/view/2742/584>.

SANTOS, L. A. C. Utilização dos dados do Cadastro Ambiental Rural na análise de conflitos de uso do solo em Áreas de Preservação Permanente. Tecnia, v. 3, n. 1, p. 174-196, 2018. Disponível em: <https://www.researchgate.net/publication/327714622 _Utilizacao_dos_dados_do_Cadastro_Ambiental_Rural_na_analise_de_conflitos_de _uso_do_solo_em_Areas_de_Preservacao_Permanente>.

SANTOS, C. D. M. dos.; MAGRI, R. A. F. Áreas verdes urbanas do município de Itaú de Minas-MG, Brasil. Enciclopédia Biosfera, v. 15, n. 27, p. 42-53, 2018. Disponível em: <http://www.conhecer.org.br/enciclop/2018a/agrar/areas\%20verdes.pdf>.

SCHEUER, J. M.; NEVES, S. M. A. da S. Planejamento urbano, áreas verdes e qualidade de vida. Revista Meio Ambiente e Sustentabilidade, v. 11, n. 5, p. 5973, 2016. Disponível em: < https://www.uninter.com/revistameioambiente/index.php/ meioAmbiente/article/viewFile/587/293>.

SILVA, M. V. e. As áreas de preservação permanente urbanas: usos sustentáveis e usos alternativos na Lei $n^{\circ}$ 12.651/2012. In: Congresso Nacional do CONPEDI, 21., 2012, Niterói. Anais do XXI Congresso Nacional do CONPEDI. Niterói: FUNJAB, 2012. Disponível em: <http://www.publicadireito.com.br/artigos/?cod=080c993fb3b5 $8 \mathrm{e} 26>$.

SILVA, J. A. B. da.; BARROSO, R. de C. A.; RODRIGUES, A. de J.; COSTA, S. S.; FONTANA, R. L. M. A urbanização no mundo contemporâneo e os problemas ambientais. Ciências Humanas e Sociais Unit, v. 2, n. 2, p. 197-207, 2014. Disponível em: <https://periodicos.set.edu.br/index.php/cadernohumanas/article/view /1723/964>.

SILVA, A. D. P. da.; SANTOS, A. F. dos.; OLIVEIRA, L. M. de. Índices de área verde e cobertura vegetal das praças públicas da cidade de Gurupi, TO. Floresta, Curitiba, v. 46, n. 3, p. 353-361, 2016. Disponível em: <https://revistas.ufpr.br/floresta/article/v iew/40052/29329 >. doi: 10.5380/rf.v46i3.40052

SILVA, R. F. de S.; MENEZES, S. J. M. da C. de.; SOUZA, M. O. A. de.; AMORIM, M. C. Cálculo do índice de arborização urbana (índice de área verde) como indicador da qualidade socioambiental para a cidade de Três Rios, RJ. In: Simpósio de Gestão Ambiental e Biodiversidade, 5., 2016, Rio de Janeiro. Anais do $5^{\circ}$ Simpósio de Gestão Ambiental e Biodiversidade. Rio de Janeiro: Universidade Fedral do Rio de Janeiro, 2016. Disponível em: <https://www.itr.ufrrj.br/sigabi/wp-content/uploads/5 
_sigabi/Sumarizado/104.pdf>.

SZEREMETA, B.; ZANNIN, P. H. T. A importância dos parques urbanos e áreas verdes na promoção da qualidade da vida em cidades. Revista Ra' e Ga, v. 29, p. 177-193, 2013. Disponível em: <https://revistas.ufpr.br/raega/article/view/30747/2148 $3>$.

TSUJII, P. K.; RIBEIRO, A. C. C.; CARNEIRO, V. A.; SILVA NETO, C. de M. e.; GONÇALVES, B. B. Uso e ocupação das áreas de preservação permanentes no sudoeste goiano. Revista de Geografia, v. 31, n. 3, p. 43-60, 2014. Disponível em: < https://www.researchgate.net/publication/301496217_USO_E_OCUPACAO_DAS AREAS_DE_PRESERVACAO_PERMANENTES_NO_SUDOESTE_GOIANO?enrich Id $=$ rgreq-927ca4b843d9e36fd6e43539e0bc620c-XXX\&enrichSource $=Y 292 Z X J Q Y W$ dlOzMwMTQ5NjIxNztBUzozNTI2NTk1MzA4OTUzNzdAMTQ2MTA5MTk5MjU3MQ\% 3D\%3D\&el=1_x_2\&_esc=publicationCoverPdf $>$. 